\title{
As novas facetas e a ameaça da gripe aviária no mundo globalizado
}

\author{
New aspects and the threat of an avian flu epidemic in a globalized world
}

Celso F. H. Granato'; Nancy C. J. Bellei

\begin{abstract}
unitermos resumo
Gripe aviária

A influenza ou, como é conhecida comumente, a gripe, é uma doença infecciosa aguda causada por

Influenza

um grupo de vírus (com mesmo nome) que acomete várias espécies de animais, desde felinos até

Doenças emergentes aves, passando por humanos. Há cerca de 10 anos têm sido descritos, inicialmente em Hong Kong, surtos de gripe causados por vírus aviários em populações humanas. A seguir, foram descritos surtos na Holanda e no Canadá. Portanto, indaga-se: o mundo corre o risco de um novo surto semelhante ao de 1918, porém com uma população mundial quatro a cinco vezes maior? Qual a velocidade de disseminação desse vírus, visto que as viagens internacionais já não são feitas em navios lentos, mas sim em jatos supersônicos que dão a volta ao mundo em algumas horas? Antes de tudo, o que torna esse vírus tão problemático? Para nós, profissionais de laboratório, é preocupante a questão do diagnóstico etiológico dessas infecções. Como ressaltamos, os quadros de gripe podem ser causados por vários agentes. Portanto, o diagnostico etiológico, básico para intervenções terapêuticas e para que se defina a ocorrência da epidemia, passa a ter relevância ainda maior.
\end{abstract}

abstract

Influenza, or as it is best known, "flu", is an acute respiratory infection caused by a virus that affects many different animal species from felines to birds, including humans. Ten years ago, initialy in Hong Kong and after that in Holand and Canada, outbreaks of avian flu have been increasingly reported in human beings. The question is innevitable: are we in the surge of a new flu pandemic like the one we had in 1918? The perspective is even worse now that we have five times the world population and the international travels are no longer made in slow-going ships but instead in super fast jet planes. For us, laboratory professionals, the question of the laboratory diagnosis is crucial. Considering that so many different viruses are associated with respiratory infections and therapeutic measures depend on this definition, this subject assumes an even greater interest.

1. Laboratório de Virologia Clínica da Universidade Federal de São Paulo (UNIFESP); live-docente da disciplina de Doenças Infecciosas e Parasitárias da Escola Paulista de Medicina (EPM/UNIFESP); chefe do Laboratório de Virologia Clínica da EPM/UNIFESP; doutor em Doenças Infecciosas e Parasitárias pela EPM/UNIFESP; professor-adjunto da Disciplina de Doenças Infecciosas e Parasitárias do Departamento de Medicina da EPM/UNIFESP; pós-doutorado no Instituto Central de Microbiologia e Imunologia da Universidade de Hamburgo, Alemanha; médico da Fleury Medicina e Saúde. 2. Professora afiliada Departamento de Medicina da UNIFESP; doutora em Doenças Infecciosas do Laboratório de Virologia Clínica da UNIFESP; coordenadora do Setor de Virus Respiratórios da Disciplina de Infectologia UNIFESP. 
A influenza ou, como é conhecida comumente, a gripe é uma doença infecciosa aguda causada por um grupo de vírus (com mesmo nome) que acomete várias espécies de animais, desde felinos até aves, passando por humanos. É uma doença conhecida há séculos e foi responsável por inúmeras epidemias relatadas por importantes personagens do passado (Hipócrates, 495 a.C.).

Estima-se que nos últimos 300 a 350 anos ocorreram entre nove e dez pandemias de influenza ao redor do mundo, o que estabelece uma média de uma pandemia a cada 30 a 40 anos.

No início do século XX, a pandemia que causou piores conseqüências em termos de vidas perdidas foi a "gripe espanhola" ocorrida no final da I Grande Guerra (1918), que teria matado cerca de 40 a 50 milhões de pessoas em todo o mundo. Essa pandemia foi causada por um tipo de vírus (influenza) classificado como H1N1 (H de hemaglutinina e N de neuraminidase). Esse agente foi recentemente recuperado a partir de cadáveres enterrados em regiões frias da América do Norte, possibilitando assim o seu detalhamento molecular, o qual sugeriu tratar-se de vírus de origem aviária.

Cerca de 40 anos depois, em 1957, esse vírus sofreu mutações e provocou nova pandemia, mas dessa vez circulando sob a forma do H2N2. Entre 1967 e 1968, novas mutações o transformaram no vírus $\mathrm{H} 3 \mathrm{~N} 2$, que gerou nova pandemia. Essas últimas ocorrências tiveram importante impacto, porém foram menos graves do que o ocorrido com a "gripe espanhola", em 1918. Como já se passaram quase 40 anos desde a última pandemia, teme-se que, em futuro próximo, ocorram novas mutações com potencial epidêmico.

Soma-se a essa preocupação o fato de que há cerca de 10 anos têm sido descritos, inicialmente em Hong Kong, surtos de gripe causadas por vírus aviários em populações humanas. A seguir, foram descritos surtos na Holanda e no Canadá. Portanto, indaga-se: O mundo corre o risco de um novo surto semelhante ao de 1918, porém com uma população mundial quatro a cinco vezes maior? Qual a velocidade de disseminação desse vírus, visto que as viagens internacionais já não são feitas em navios lentos, mas sim em jatos supersônicos que dão a volta ao mundo em algumas horas? Antes de tudo, o que torna esse vírus tão problemático?

Os vírus do grupo influenza são microrganismos cujo material genético é constituído por oito segmentos de ácido ribonucléico (RNA), com a propriedade de se reagrupar em combinações praticamente infinitas. Cada vez que há recombinação de seu genoma entre si ou com vírus de outras espécies animais, ou mesmo quando ele sofre mutações pontuais, surge um vírus cujo efeito na população é desconhecido devido à falta de experiência ou contato anterior, portanto, ela pode ser suscetível a esse microrganismo. Se a alteração genética for significativa e boa parte da população tiver sensibilidade ao novo agente, o risco de disseminação rápida e concomitante do vírus na maior parte do planeta é real e preocupante, ou seja outra pandemia.

Com base nos dados então disponíveis, os pesquisadores acreditavam que os seres humanos se infectassem apenas com os vírus $\mathrm{H} 1$, H2 e H3, em geral após uma adaptação do vírus em suínos. Os demais vírus com hemaglutininas $(\mathrm{HA})$ de $\mathrm{H} 4$ até $\mathrm{H} 16$ infectariam apenas animais, principalmente seus hospedeiros naturais, as aves aquáticas. Contudo, a partir de 1997, demonstrou-se que somos potencialmente vítimas de vírus com outras hemaglutininas $(\mathrm{H} 5, \mathrm{H} 7$ e H9) e que, pelo menos em princípio, podemos ser contaminados diretamente a partir de aves. Embora nunca se tenha demonstrado cabalmente que esses vírus aviários, após contaminar seres humanos, pudessem ser transmitidos a outros seres humanos, a probabilidade é grande, visto que bastaria o vírus sofrer pequenas alterações para que ele se tornasse transmissivel entre humanos.

A China e os demais países do Sudeste asiático são considerados verdadeiras usinas geradoras de novos vírus, uma vez que albergam grande número de aves aquáticas migratórias e imensas criações de aves de corte ao lado de fazendas com milhões de suínos contamináveis por vírus aviários. Além disso, os seres humanos contaminados com esses vírus adaptados ao homem poderiam adquirir mutações adicionais que permitissem a transmissão inter-humana. Assim, fecha-se o circuito para uma nova epidemia.

Naturalmente, as conseqüências de uma nova pandemia poderiam parecer menos graves nos dias atuais. Afinal de contas, em 1918 não tínhamos antibióticos, antivirais, drogas vasoativas, unidades de terapia intensiva (UTIs) e ventiladores artificiais. Por outro lado, ao analisar os registros de autópsias dos pacientes falecidos naquele ano, nota-se que, em termos relativos, morreram mais jovens do que idosos; contrariamente ao que se vê desde então. Além disso, muitas mortes ocorreram devido a sangramento pulmonar, ocorrência ainda hoje de difícil abordagem terapêutica. Justifica-se, portanto, os temores de que nova epidemia causada por vírus aviários poderia ter conseqüências desastrosas.

O que se espera de uma pandemia de gripe aviária atualmente?

Os dados mais confiáveis que dispomos são os dos EUA, onde se estima que cerca de $10 \%$ a $20 \%$ da população 
contrai gripe uma vez em cada inverno. Isso resulta em 114 mil internações, com 36 mil mortes (dados da década de 1990). Atualmente, cerca de $90 \%$ desses óbitos são de idosos. A pneumonia associada à influenza é a sexta causa de morte nos EUA. Projeta-se que uma pandemia nos dias atuais levaria à morte entre 2 e 7,4 milhões de americanos e a um aumento de $25 \%$ na demanda de ventiladores e leitos das UTIs. Portanto, pode-se cogitar que os custos de uma epidemia dessa magnitude seriam astronômicos.

Por que a gripe aviária é mais agressiva do que as gripes comuns?

Para exercer seu papel patogênico, o vírus precisa entrar na sua celular hospedeira, porquanto não dispõe de maquinaria para gerar energia e síntese protéica. Essa entrada se faz pela ligação de uma proteína viral (hemaglutinina [HA]) com um receptor celular derivado do ácido siálico. A HA é sintetizada sob uma forma precursora que requer clivagem enzimática para sua atuação; dependendo da seqüência de aminoácidos da HA, haverá necessidade de uma determinada protease para que isso ocorra. Esse fato acaba determinando o tropismo viral.

Em pássaros aquáticos a replicação do influenza ocorre no trato gastrointestinal sem apresentar sintomas. Já em humanos e suínos, essa replicação é restrita às células epiteliais do trato respiratório, nas quais exerce seu efeito patogênico. Em mamíferos, essa protease parece ser a triptase clara, uma serina protease produzida pelas células claras não-ciliadas dos epitélios brônquico e bronquiolar, e a sua expressão está consideravelmente aumentada durante a infecção pelo influenza. Mutações nessa seqüência de HA podem resultar em disseminação do vírus influenza para outras células. Casos de inserção de aminoácidos básicos tornam a seqüência mais facilmente clivável (formam sítio polibásico) e, conseqüentemente, mais tipos de proteases podem atuar, como as endoproteases furina e serina PC6 que estão presentes em praticamente todas as células de aves. No caso do ovo embrionado, o vírus replica normalmente na endoderme da membrana corioalantóica (CAM), mas esse tipo de mutação torna permissiva a replicação viral também na mesoderme e ectoderme, que resulta na morte do embrião.

Estudos in vitro demonstraram que o aumento da patogenicidade do influenza também pode ocorrer com algumas cepas de HA monobásicas, seja por coinfecção com bactérias que induzem, direta ou indiretamente, proteases capazes de ativar HA e/ou mutações que resultam em mudança conformacional, que a torna acessível a outras serinas proteases e até mutações maiores no sítio de cliva- gem, tornando-a clivável por outras classes de proteases (ROTT, 1995).

Esse mecanismo de aumento da patogenicidade tem sido descrito para os vírus $\mathrm{H} 5$ e $\mathrm{H} 7$ envolvidos em grandes surtos epidêmicos entre as aves. $\mathrm{O}$ acréscimo de tipos celulares que clivam a HA se deve principalmente à mudança na seqüência monobásica, com a substituição de uma arginina por uma série de resíduos básicos, gerando um motivo de reconhecimento Arg-X-Lys/Arg-Arg ( $X$ é um aminoácido não-básico) para a endoprotease furina (tribásico).

Outro mecanismo que tem sido aventado para explicar o aumento da patogenicidade do vírus influenza envolve mudança conformacional, que permite o acesso ao sítio de clivagem monobásico por outras serinas proteases. A partir disso, a clivagem torna-se possível por enzimas envolvidas na resposta inflamatória, como plasmina, calicreína, uroquinase e trombina, que podem ativar algumas cepas de $\mathrm{HA}$, exceto a tripsina. Associado a isso, também tem sido descrita a presença de uma cadeia de carboidratos que impede a acessibilidade de outras proteases, nas quais a perda desse carboidrato torna a HA mais clivável e mais patogênica.

Por último, enzimas secretadas por bactérias Staphylococcus aureus e Streptococcus viridans apresentam atividade de clivagem sobre algumas HA monobásicas, o que pode, nos casos de co-infecção, resultar num sinergismo patogênico. Casos de indução indireta no aumento da patogênese do influenza podem ocorrer nas co-infecções por Serratia marcescens e Pseudomonas aeruginosa. Essas bactérias levam à indução de enzimas tripsina-like inflamatórias no lavado bronquicoalveolar, que podem ativar cepas de HA sensíveis, como em casos de indução da secreção de plasmina por estreptoquinase (SK) e estafiloquinase (ROTT, 1995).

Outra hipótese para explicar a gravidade da gripe aviária seria que a patogenia fosse decorrente da excessiva produção de citocinas pró-inflamatórias e quimiocinas por parte de várias células, tanto do endotélio vascular, como também macrófagos e células T. Essas substâncias atuariam nos pulmões, ocasionando síndrome do desconforto respiratório agudo (SDRA), destruição tecidual, influxo de neutrófilos e dilatação dos vasos sangüíneos. Tal situação explicaria as graves lesões observadas nos pacientes jovens em 1918 e os quadros relativamente mais brandos nos idosos de então.

Toda essas alterações patogênicas relacionadas ao vírus H5N1, quando em comparação com aquelas associadas ao vírus H3N2 que normalmente infecta a espécie humana, 
provavelmente são responsáveis pelo quadro atípico da gripe aviária em relação à gripe comum: período de incubação mais prolongado (5-17 dias); febre elevada com ausência de sintomas do trato respiratório superior com evolução rápida e freqüente para pneumonia viral primária; diarréia aquosa; encefalopatia; insuficiência renal e choque. Assim, muitas vezes, se não há o antecedente epidemiológico de contato com aves infectadas, o quadro clínico pode simular muitas outras doenças infecciosas com evolução grave.

O tratamento da gripe tem sido feito tradicionalmente à base de sintomáticos, descongestionantes, antitérmicos e cuidados gerais de hidratação. No caso das gripes aviárias tem sido sugerido o uso de uma nova classe de drogas, os inibidores de neuraminidase (NA). Essa glicoproteína é responsável pela liberação dos vírus a partir da célula hospedeira e pela contaminação de outras células. Se obtiver sucesso na inibição dessa enzima, em princípio, haverá menor liberação de vírus e a doença deve ter um curso mais limitado.

Foram desenvolvidas duas drogas dessa classe, o oseltamivir e o zanamivir. A primeira delas é de uso oral e já há alguma experiência com seu manuseio. Pode-se afirmar que, para melhor exercer seu potencial terapêutico, o tratamento deve ser instituído muito precocemente, o que pode gerar indicações desnecessárias, com os efeitos colaterais daí decorrentes. Além disso, seu uso em escala maior, como ocorreu no Japão, especialmente entre crianças, levou à geração de resistência em níveis preocupantes para uma classe de drogas de uso tão recente (20\%). De qualquer forma, face à indisponibilidade de alternativas mais efetivas e devido à eficácia em determinadas situações, houve uma corrida desenfreada aos produtores e a formação de estoques da droga em vários países.

Outra medida profilática importante refere-se à vacinação. Há décadas emprega-se a vacinação como forma de prevenção da gripe. Ao longo do ano, uma série de médicos-sentinela colhem material de pacientes com gripe e os envia a laboratórios de referência para que seja feita a caracterização do agente causal ( $\mathrm{H}$ e N). Esses laboratórios (no caso do Brasil, o Instituto Adolfo Lutz, a Fundação Oswaldo Cruz [FIOCRUZ] e o Instituto Evandro Chagas [IEC]) encaminham essas amostras para maior detalhamento da caracterização viral e, periodicamente, faz-se uma estimativa de qual seriam as cepas de vírus com maiores chances de circular no próximo inverno. São definidas três cepas que farão parte do coquetel de vacinas do ano (duas delas constituídas por $\mathrm{H} 1$ e H3).

Quando a previsão dá bons resultados e não há mutações inesperadas, diz-se que o match foi bom e a vacina será altamente eficaz. Quando o vírus sofre mutações e, dependendo do grau dessa mutação, a semelhança entre os vírus vacinais e aquele que efetivamente circula na população é pequena, a vacina poderá ter pouca eficácia.

Também deve ser ponderado que existem vários outros vírus que podem causar sintomas bastante semelhantes à gripe (vírus respiratório sincicial [VRS], adenovírus, parainfluenza, rinovírus, entre outros) para os quais a vacina não oferece qualquer proteção. Isso gera descrença entre os indivíduos vacinados e o conceito de que "eu tomei a vacina e tive gripe do mesmo jeito". Em decorrência disso, a aderência da população à vacinação contra gripe é abaixo da ideal.

Além disso, nunca houve justificativa para que a vacina contivesse vírus com outras hemaglutininas $(\mathrm{H} 5, \mathrm{H} 7 \mathrm{ou} \mathrm{H9})$, visto que, conforme mencionado anteriormente, não se imaginava que pudéssemos nos infectar com esse tipo de vírus. Após os surtos de "gripe aviária" em humanos, esse risco tornou-se real e passou-se a pensar na possibilidade de incluir outros tipos de vírus na vacina.

A vacina da gripe é preparada a partir da inoculação do vírus "candidato" em ovo embrionado. $\mathrm{O}$ vírus então se multiplica nos tecidos do ovo, gerando uma quantidade de antígenos suficiente para se preparar uma dose de vacina ( 1 ovo $=1$ dose). Além dessa limitação (baixo rendimento), todo o processo é lento: após a definição do subtipo de vírus, e até a efetiva concretização da dose vacinal podem se passar cerca de três a quatro meses.

Por essa razão, embora seja uma medida muito importante e necessária, a produção de vacinas contra vírus "não-tradicionais" não é um processo simples e rápido. Soma-se a isso o fato de que as vacinas produzidas até agora, ainda em nível de investigação, não apresentaram os efeitos esperados em termos de níveis de anticorpos e potencial de neutralização. Apenas no final de abril deste ano é que a Food and Drug Administration (FDA), órgão que regulamenta produtos dessa natureza nos EUA, aprovou a primeira vacina para uso comercial em seres humanos.

Não há registros da ocorrência de surtos do vírus H5N1 em aves nos países das Américas do Norte e do Sul até o momento, mas recomenda-se a investigação de pacientes sintomáticos de viagens internacionais procedentes de áreas de risco que tenham histórico de contato com aves. Diante do controle incerto da epidemia de H5N1 e da possibilidade de maior disseminação da infecção humana, com mudança no padrão de transmissão, é importante que a comunidade de profissionais da área da saúde mantenha-se atenta e informada para atuar com maior eficiência em diferentes cenários epidemiológicos da dinâmica da infecção do vírus influenza, lembrando que nova pandemia poderá surgir também por combinações entre diversos vírus influenza, originando um H2N2, por exemplo, que atualmente não circula entre os humanos. Isso poderia ter um impacto pandêmico. 


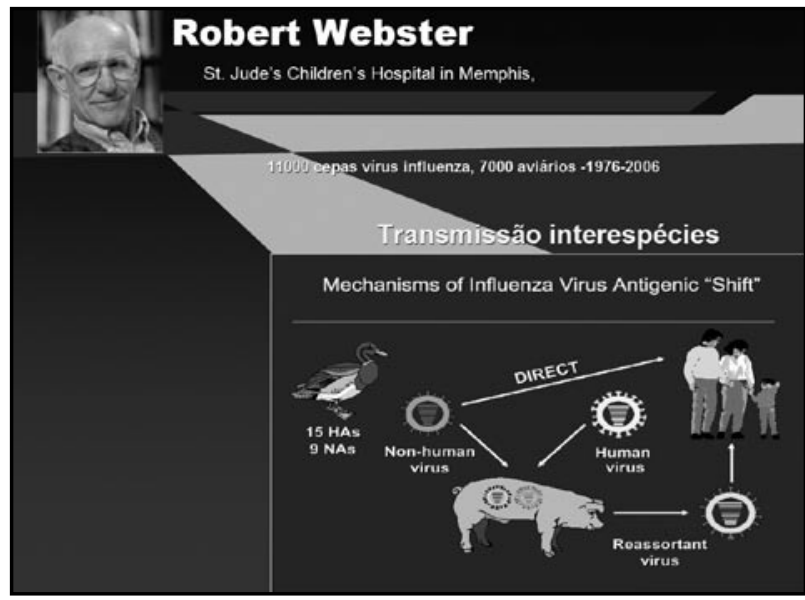

Figura 1 - Hipóteses para a disseminação do vírus Influenza a partir de aves para suínos e seres humanos, segundo o pesquisador Robert Webster

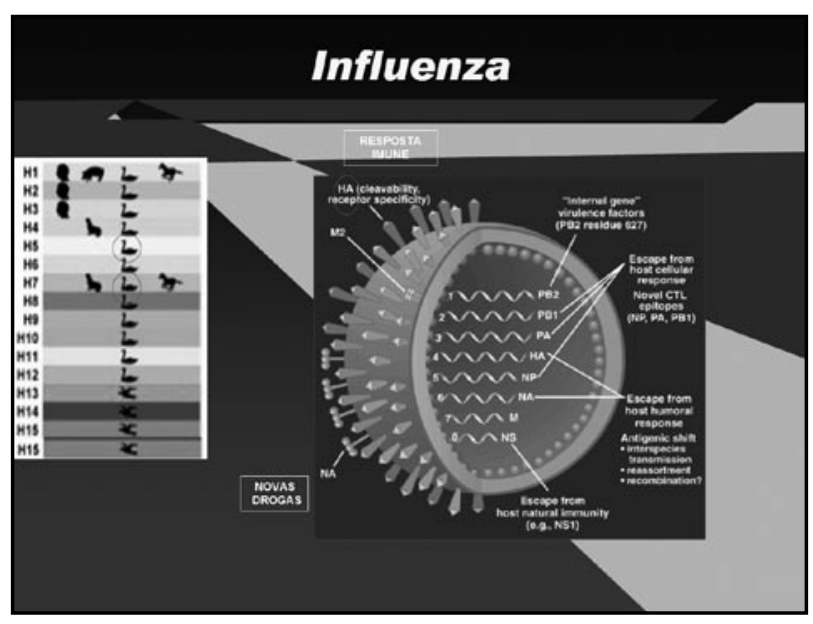

Figura 2 - Representação esquemática do vírus Influenza com detalhamento de suas proteínas e genoma. Espectro de distribuição da hemaglutinina entre espécies animais

Para nós, profissionais de laboratório, é preocupante ainda a questão do diagnóstico etiológico dessas infecções. Como ressaltamos, os quadros de gripe podem ser



Figura 3 - Variedade de agentes virais associados a quadros respiratórios e sua localização preferencial no trato respiratório

causados por vários agentes. Portanto, o diagnóstico etiológico, básico para intervenções terapêuticas e para que se defina a ocorrência da epidemia, passa a ter relevância ainda maior.

O diagnóstico dessas afecções ainda é restrito a poucos laboratórios, se bem que a metodologia seja dominada há muitas décadas. Emprega-se mais freqüentemente a imunofluorescência, usando anticorpos monoclonais dirigidos contra uma série desses vírus. Dessa forma, pode-se definir claramente qual seria o agente de grande parte desses casos, embora cerca de $20 \%$ a $30 \%$ deles, fora dos períodos epidêmicos, possam ser associados a agentes não detectáveis pela imunofluorescência (rino e coronavírus). De qualquer forma, seja para diagnóstico individual e a conseqüente medida terapêutica, seja para a definição do eventual início de um surto epidêmico, o profissional de laboratório tem papel importantíssimo a cumprir no campo das doenças respiratórias, devendo estar preparado técnica e cientificamente para responder às necessidades da comunidade.

\section{Referências}

1. KLENK, H.D.; ROTT, R. The molecular biology of influenza virus pathogenicity. Adv Virus Res, v. 34, p. 247-81, 1988.

2. ROTT, R. et al. Influenza viruses, cell enzymes, and pathogenicity. Am J Respir Crit Care Med, v. 152, n. 4 Pt 2, p. 16-9, 1995.

3. LAL, S.K.. Biology of emerging viruses: SARS, avian and human influenza, metapneumovirus, Nipah, West Nile, and Ross River virus. Ann N Y Acad Sci, v. 1102, p. 1-25, 2007.

4. LYNCH, J.P.; WALSH, E.E. Influenza: evolving strategies in treatment and prevention. Semin Respir Crit Care Med, v. 28, n. 2, p. 144-58, 2007.

5. MALIK PEIRIS, J.S.; JONG, M.D.; GUAN, Y. Avian influenza virus (H5N1): a threat to human health. Clin Microbiol Rev, v. 20, n. 2, p. 247-67, 2007.

Endereço para correspondência

Celso Granato

Rua Pedro de Toledo, 781 - $15^{\circ}$ andar Vila Clementino CEP 04039-032 - São Paulo-SP Telefax: 55 (11) $5081-5394$ e-mail: celso.granato@fleury.com.br 